\title{
Nucleosomal Repeat Length
}

National Cancer Institute

\section{Source}

National Cancer Institute. Nucleosomal Repeat Length. NCI Thesaurus. Code C13657.

Nucleosomal repeat length is approximately 200 base pairs of DNA within which 146

base pairs are highly protected. $(\mathrm{NCl})$ 